\title{
Some Aspects of the Biology and Behaviour of Sesamia nonagrioides botanephaga Tams and Bowden (Lepidoptera: Noctuidae), a Major Stem Borer Pest of Maize in Southern Ghana
}

\author{
S. T. S. Ateyim ${ }^{1}$, D. Obeng-Ofori ${ }^{1}$, M. A. Botchey ${ }^{2}$ and E. O. Owusu ${ }^{1}$ \\ ${ }^{1}$ African Regional Postgraduate Programme in Insect Science (ARPPIS), University \\ ${ }^{2}$ Department of Zoology, University of Cape Coast, Cape Coast, Ghana
}

\author{
of Ghana, Legon
}

\begin{abstract}
Studies were conducted on the stemborer, Sesamia nonagrioides botanephaga Tams and Bowden (Lepidoptera: Noctuidae), which is a pest of increasing importance on maize in Ghana, to elucidate some aspects of its biology and behaviour in southern Ghana. The pest was more abundant in the minor season than in the major season. The life cycle revealed 10 developmental stages, namely the egg, six larval instars, prepupa and pupa. A female S. n. botanephaga laid eggs within a period of 5 days. The eggs were deposited on the inner side of the leaf sheath fitting tightly onto the maize stem. The mated females laid more eggs per female (330 \pm 17.7 eggs) than the virgin females ( $268 \pm 9.2$ eggs). The incubation period of the eggs was $5.23 \pm 0.03$ (5-7) days. The mean larval duration was 29 days and the prepupal period lasted for $1-3$ days. The first instar larvae dispersed within 1-3 days after hatching. The third, fourth, fifth, and sixth instar larvae fed actively on maize stalk producing large quantities of frass. The pupal period varied from 6 to 10 days. The life cycle was completed in an average of 35.2 (26-51) days. Adults of S. $n$. botanephaga lived for between 4-10 days. The adults reared in the laboratory showed a sex ratio of 2:3 (male : female), which was significantly different from the expected ratio (1:1). The implications of these findings are discussed in relation to the effective management of the pest in Ghana.
\end{abstract}

\section{Introduction}

Maize (Zea mays) is one of the world's most important cereal crops. Its wide genetic diversity and multiple uses account for its cultivation in a large range of environments (IITA, 1991). The demand for maize as food and feed is expected to increase at $4.1 \%$ per annum in the developing countries, with an increase in demand projected at 3.2\% per annum in the sub-Saharan Africa (Byerlee \& Saad, 1993). More than 700 million people in the developing world do not have access to sufficient food to meet their need for healthy and productive life (Lisa, Amani \& Jensen, 2000). Increase in maize production especially in the rural areas can help reduce the hungry population in the developing countries.

Maize is a tall gramineae with a large stalk and long leaves. It is one of the most important crops in Africa and is generally cultivated by small-holder farmers (FAO, 1992). The low yields of maize in Africa results from the interaction of factors which include the volume and distribution of rainfall, soil fertility, inefficiency of prevailing crop management practices and biotic factors comprising diseases and insect pests.

The bulk of maize in Ghana is produced in the guinea savanna zone (Brong-Ahafo and Northern regions) (Gounou et al., 1993). In this agro-ecological zone, maize production is intensive but numerous diseases and insect pests, particularly stem borers, erratic rainfall and high temperatures limit yields (Kwapong, 1990). In areas with a bimodal rainfall, stem borer population generally reaches climax during the minor cropping season where total crop loss due to stem borer attack is not uncommon (Adeyemi, Donelly \& Odetoyimbo, 1966; Girling, 1980).

Several species of maize stemborers have been reported in Ghana but the most notorious ones are Sesamia calamistis Hampson (Lepidoptera: Noctuidae), Eldana saccharina Walker (Lepidoptera: Pyralidae) and Busseola fusca Fuller (Lepidoptera: Noctuidae) (Abu, 1986). Significant reduction in yield due to stem borers has been reported in all the major maize producing areas in the country (Bowden, 1956, 1976; Girling, 1980). The larvae of stem borers usually cause the damage. Their feeding leads to death of the growing points, early senescence, 'dead heart' condition, reduced translocation, lodging and indirect damage to the ears (Appert, 1970; Breniere, 1971). Estimated yield losses caused by stem borers in West Africa range from 10-100\% (Usua, 1968). The story is not different from other parts of Africa where most peasant farmers do not plant the minor season maize due to total loss caused by stem borers (Gounou et al., 1993).

For effective control of an insect pest, knowledge of its life history, biology and ecology are critical (Sampson \& Kumar, 1984). S. $n$. botanephaga was first dis-cribed by Tams \& Bowden (1953), but there is no information on its life cycle (Ateyim, 1999). Leyenaar \& Hunter (1977) reported that $S$. $n$. botanephaga can cause $63 \%$ loss in yield of maize in the coastal savanna of Ghana. The oviposition site of $S$. $n$. botanephaga is not known. This study sought to determine the behaviour and some aspects of the biology of S. n. botanephaga, in particular, to determine its oviposition site and, hence, the location of the first instar larvae which is the most vulnerable stage of the insect. This information is important for the management of the pest before they disperse. 


\section{Experimental site}

\section{Materials and methods}

The study was carried out on the field and in the laboratory. The laboratory studies were carried out in the Zoology Department of the University of Cape Coast and the field study was undertaken at the University of Cape Coast Teaching and Research Farm, located $5 \mathrm{~km}$ away from the Science Faculty. Crops cultivated in the farm include maize, cassava, sweet potato, okra, egg-plant, pineapple, citrus and coconut. Cropping is done throughout the year. In the minor season when there is little or no rain, the crops are irrigated. The experiments were undertaken in both the minor and the major seasons.

\section{Land preparation and planting}

Two plots measuring $30 \mathrm{~m} \times 20 \mathrm{~m}$ were prepared by ploughing and harrowing. The minor season maize was planted in early November and the major season one in late March. The maize was planted in rows with a planting distance of $90 \mathrm{~cm}$ between rows and $30 \mathrm{~cm}$ between hills on rows. This was thinned on emergence to two plants per hill. Uprooted maize stems were used for feeding the insects in the laboratory. The maize variety, "Obatampa”, was used for the study. Hoeing was done 3 and 8 weeks after planting to control weeds. No insecticide was applied to the plants.

Field survey and collection of stem borers

In addition to the study site at the University of Cape Coast, a number of maize fields were surveyed for the presence of the larvae and pupae of stem borer species, which were collected for identification in the laboratory. The areas visited were Kakum, Praso, the Holy Child School, Mankessim and the University campus. The minor cropping season's survey was carried out from November to March while that of the major season was from April to June. Maize plants in the field were examined for stem borer damage. Infested plants were recognized by the presence of frass and borer holes on the stem or wilting of young plants. The infested plants were cut open vertically to expose the larvae and pupae, which were then collected and sent to the laboratory.

\section{Identification of Sesamia species}

Species of Sesamia found in the Central Region of Ghana were identified using the taxonomic keys prepared by Tams \& Bowden (1953). The character used was the adult genitalia. The larvae and pupae collected were brought to the laboratory and reared to adults.

\section{Rearing of larvae in the laboratory}

Each larva was reared singly in a $200 \mathrm{ml}$ rearing bottle whose top was covered with nylon mesh. The larvae were fed with pieces of maize stem every other day. Newly hatched first instar neonate larvae were isolated singly into Petri dishes containing moistened filter paper and fresh young maize leaves with part of the sheaths attached to it. The Petri dishes were covered to prevent the young larvae escaping. Older instars (from 3rd to 6th) were fed with fresh maize stems. Each larva was weighed every other day at the time of change of feed with a sensitive chemical balance. The moulting stages were recognized by the presence of the head capsule or cast skin through careful examination of the frass. The width of head capsule was measured after each moult using a graduated microscope $(2 \times)$. A thermohydrograph was used to measure daily temperature and relative humidity.

\section{Sexing and mating}

It is difficult to distinguish the male from the female at the larval stage of $S$. $n$. botanephaga. Sexing was, therefore, done at the pupal stage because the pupa shows a very distinct sexual dimorphism, which makes sexing quite simple with the aid of a binocular microscope. The male shows through the cuticle a hump at the genital position but this is lacking in the female. However, the adult of both species can be distinguished easily in that the adult male has bipectinate antennae while the female has filiform antennae. On emergence from the pupal case, an adult male and female were paired in a kilner jar $(450 \mathrm{ml})$, which was covered with nylon mesh to prevent the moth from escaping. Unpaired females were also put in separate jars.

\section{Oviposition in the laboratory}

Eggs were collected from the kilner jars in which the male and female insects were paired and singled. Leaf sheath and folded filter papers were put into the kilner jars for the females to lay eggs on. The kilner jars were changed daily to collect and record eggs laid by each female. The eggs were counted using a binocular microscope and hand lens. The total number of eggs laid per mated and unmated female per day was recorded. This was done until egg laying was completed just before the death of the insect. The oviposition period was also recorded.

\section{Oviposition on potted maize plants in cages}

"Obatanpa" maize was planted singly at 3-week intervals in 24 plastic buckets and put into cages measuring $(0.9 \times$ $0.9 \times 1.8 \mathrm{~m}$ ). These buckets, containing three growth stages of maize plants (pre-tasselling, tasselling and silking 
stages) in each cage, were replicated five times. In each cage five pairs of newly emerged male and female borers were released. After 2 days, all the plants were removed and searched for the sites where the females laid the eggs. Each plant was divided into three parts (the upper, middle and lower). The number of eggs deposited on different plant parts and stages were recorded.

\section{Egg size and incubation period}

One hundred eggs laid in the laboratory were randomly sampled and their length and width measured using a graduated slide and a binocular microscope. Infertile eggs were discarded. The fertilized eggs after counting were placed in Petri dishes containing moistened filter paper. Daily observations were made to record any visible change on the eggs. The number of eggs that hatched was recorded, as well as the incubation period.

\section{Larval and pupal stages}

Fresh pieces of stems cut from the maize plants in the field were used to feed the larvae. Feed was changed every other day by carefully dissecting to remove the larvae from the previous stem pieces. Moulting was indicated by the presence of cast skin and/or head capsule measurement. The total number of moults as a measure of the number of instars was recorded. Each larva was weighed every other day when fresh feed was given to the larvae. Width of head capsule found in the frass was recorded. The larvae were observed till pupation. Each pupa was weighed and the length and width were measured. The pre-pupae and pupae were kept in the rearing bottles until adult emergence. The larval and pupal mortality was recorded.

\section{Adult stage}

The adults were kept in pairs or singly in the kilner jars to study longevity, fecundity and mating bahaviour. They were observed in darkness using red light from the torch. The eggs laid by the females were isolated, counted and used for further studies.

\footnotetext{
Results

Composition and population structure of stem borer species

The species of stem borers found on maize in the study area were Eldana saccharina Walker, Sesamia calamistis Hampson, S. nonagriodes botanephaga Tams and Bowden, and Chilo aleniellus (Strand). Stem borers were present in both the minor and major cropping seasons and their abundance varied with the species and the stage of the plant growth. E. saccharina and the two Sesamia species were more abundant in the minor cropping season than in the major season. In contrast, $C$. aleniellus was more abundant in the major cropping season than in the minor season (Fig. 1 and 2). Sesamia species were more abundant on younger plants (pre-tasselling) than the older plants (mature plants) while E. saccharina and C. aleniellus were found more on the matured plants than the younger ones (Table 1). Life cycle of S. n. botanephaga
} 


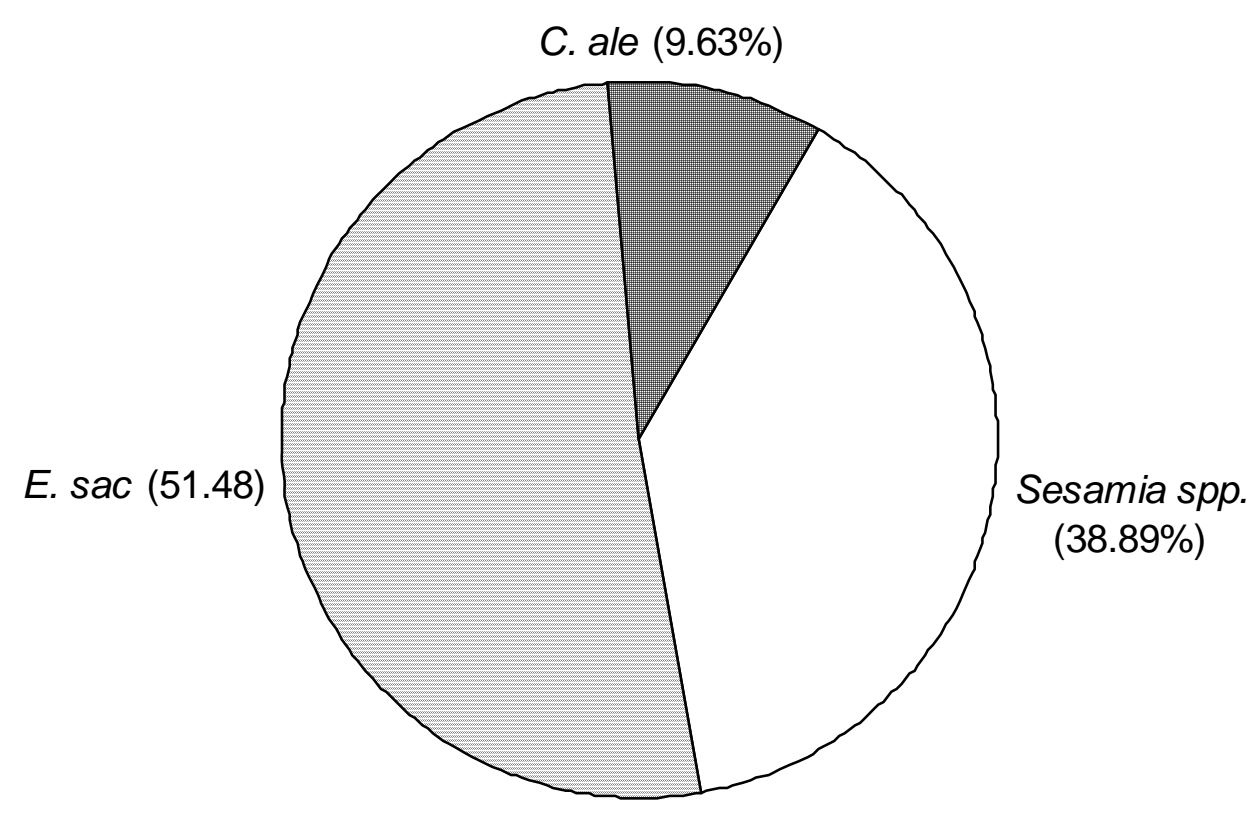

Fig. 1: Relative abundance of stemborer species in the minor season

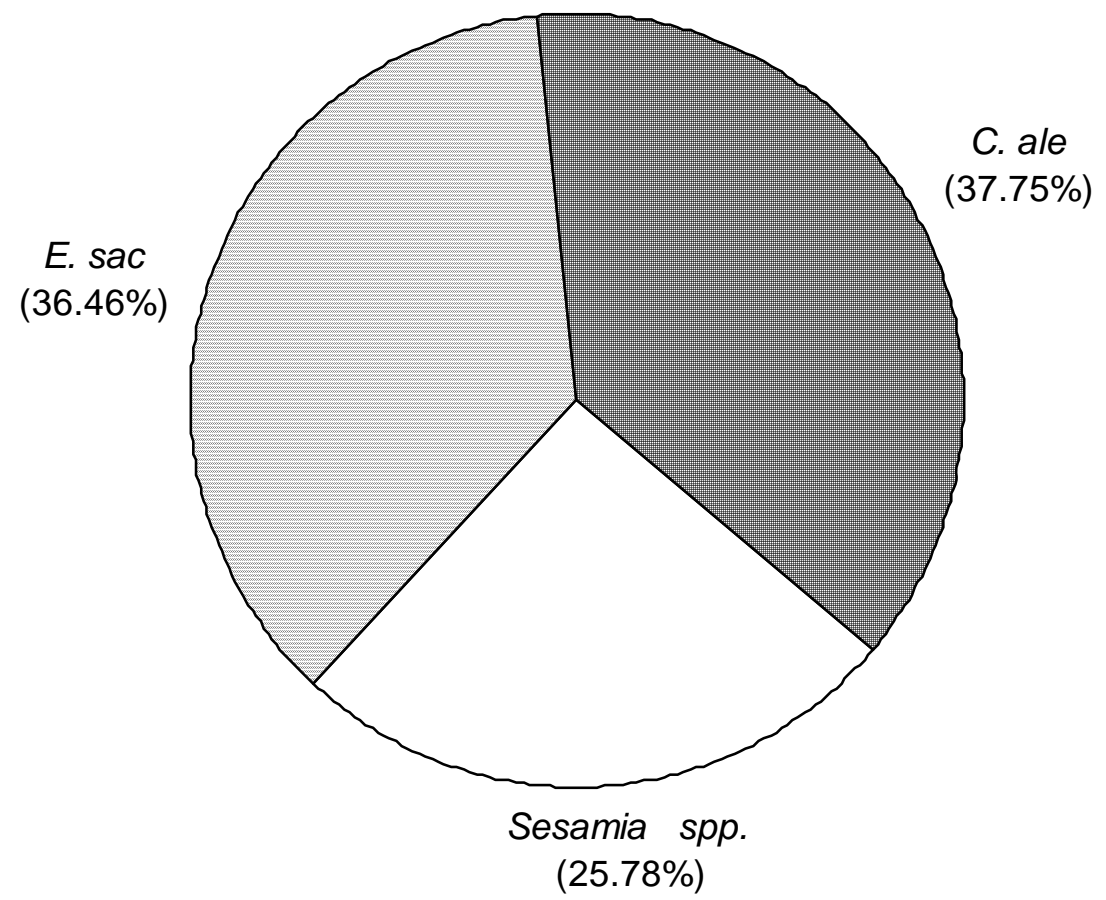

Fig. 2: Relative abundance of stemborer species in the major season

TABLE 1

Relative abundance of stem borers at different stages of plant growth
E. saccharina
Sesamia $s p$.
C. aleniellus 


$\begin{array}{llll}\text { Pre-tasselling } & 8.45 \pm 1.23 & 10.24 \pm 1.94 & 1.90 \pm 0.48 \\ \text { Tasselling } & 11.35+2.13 & 5.14 \pm 1.74 & 2.20 \pm 0.39 \\ & & & \\ \text { Major season } & & & \\ \text { Pre-tasselling } & 3.93 \pm 31 & 8.41 \pm 2.86 & 4.35 \pm 1.98 \\ \text { Tasselling } & 5.03+2.6 & 3.65 \pm 0.43 & 10.73 \pm 2.64\end{array}$

The mean developmental period of $S$. $n$. botanephaga from egg to adult was $35.2 \pm 0.28$ in the range of $26-51$ days (Table 2).

TABLE 2

Mean duration of developmental stages in the life cycle of S .n. botanephaga

$\begin{array}{lll}\begin{array}{l}\text { Developmental } \\ \text { stage }\end{array} & \begin{array}{l}\text { Duration } \pm \text { S.E. } \\ \text { (days) }\end{array} & \begin{array}{l}\text { Range } \\ \text { (days) }\end{array} \\ \text { Egg } & 5.23 \pm 0.03 & 5-7 \\ \text { 1st instar } & 2.63 \pm 0.17 & 2-4 \\ \text { 2nd instar } & 2.00 \pm 0.16 & 2-4 \\ \text { 3rd instar } & 5.20 \pm 0.21 & 3-7 \\ \text { 4th instar } & 5.32 \pm 0.21 & 4-7 \\ \text { 5th instar } & 4.00 \pm 0.34 & 2-6 \\ \text { 6th instar } & 1.70 \pm 0.13 & 1-4 \\ \text { Prepupal stage } & 1.00 \pm 0.01 & 1-3 \\ \text { Pupal stage } & 8.12 \pm 0.08 & 6-9 \\ \text { Total } & 35.2 \pm 0.28 & 26-51\end{array}$

Minimum and maximum temperatures of $22.95 \pm 0.6{ }^{\circ} \mathrm{C}$ and $32.1 \pm 0.2{ }^{\circ} \mathrm{C}$, respectively and $78.0 \%$ r.h.

\section{The egg stage}

Eggs of S. $n$. botanephaga have a flat top and bottom measuring $0.85 \pm 0.02 \mathrm{~mm}$ in length and $0.36 \pm 0.01 \mathrm{~mm}$ in width. They are white when first laid but change to pale orange as they approach hatching.

\section{Choice of oviposition site}

In the laboratory, when adult moths were placed in the kilner jars, eggs were laid on the lid, rim and inner surface of the jars. When the jars were provided with filter paper and pieces of fresh stalks, eggs were deposited in the folds of the filter paper and leaf sheath. Those laid on the leaf sheath were neatly arranged into a long row on the inner side closer to the edge.

In the case of the potted plants in the cages, eggs were laid on the inner side of the leaf sheath of the maize plants. It was observed that more eggs (with a mean number 39.5) were laid on the pre-tasselling maize plants than on the tasselled (with mean number of egg 31.2) and the plants with silk (with mean number 26.3). The part of the plant most preferred by the moths for egg laying was the middle portion with a mean number of 71.0 eggs $(\mathrm{p}<0.05)$ compared to the upper and lower portions of the plant with mean numbers of 18.3 and 14.4 eggs, respectively. In the field, therefore, female of $S$. $n$. botanephaga preferred laying her eggs on the middle portion of the maize plant than the upper and the lower portions.

\section{Fecundity and egg fertility}

The mean number of eggs laid per mated female was 330.2 \pm 17.7 eggs and that of unmated female $268.2 \pm 9.2$ eggs. This indicated that the mated females laid more eggs than the unmated females. The females (mated and unmated) began laying eggs on the second night after emergence and laid throughout for a maximum of 5 days. The number of eggs laid per female increased from the first day reaching its peak on the third day and decreasing till the 5th day when laying was completed (Fig. 3). 


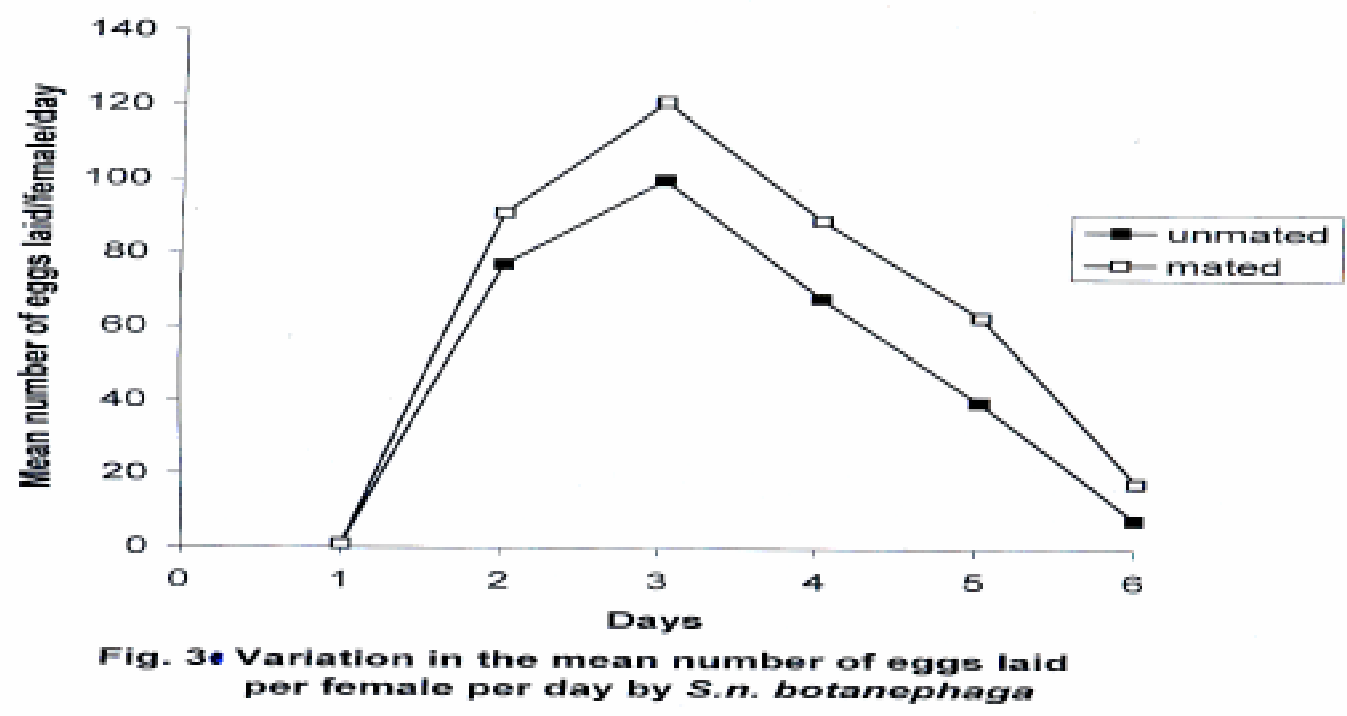

Incubation period

The total number of eggs laid in the laboratory and those collected from the field was 9,872 and out of these 5,213 hatched (53\%). The mean incubation period was $5.23 \pm 0.02$ range 5-7 days at a mean minimum and maximum temperature of $22.95 \pm 0.6^{\circ} \mathrm{C}$ and $32.1 \pm 0.2{ }^{\circ} \mathrm{C}$, respectively, and $78.0 \%$ relative humidity.

\section{Larval stage}

The larva of $S$. $n$. botanephaga is a buff or pinkish caterpillar with more or less distinct black spots along the body representing the position of the spiracles. It has a pale ventral part. The length and width of different larval stages are shown in Table 3. The mean width of the head capsule of the different larval instars of $S$. $n$. botane-phaga is also shown in Table 4. There are six larval stages. The first neonate larva is very small with brown and sclerotized head. The mandibles are not well developed and the head is retracted into the pro-thorax. It has a mean length and width of $3.26 \pm 0.12 \mathrm{~mm}$ and $1.28 \pm 0.12$, respectively. The second instar larva is longer and larger than the first instar with a mean length and width of $6.09 \pm 0.13$ and $1.84 \pm 0.13 \mathrm{~mm}$, respectively. It has a head capsule width of $0.94 \pm 0.02$ $\mathrm{mm}$. The head of the third instar larva is highly sclerotized and deep violet in colour. It has a mean length and width of $16.34 \pm 0.5 \mathrm{~mm}$ and $3.21 \pm 0.2 \mathrm{~mm}$. The marking segments are more distinct in the third instar than the second. The mean third instar larval duration was $5.2 \pm 0.21$ (3-7) days.

TABLE 3

Dimensions of the different stages of S. $n$. botanephaga reared in the laboratory

\begin{tabular}{lrrrrrrr}
\multicolumn{4}{c}{ Length $(\mathrm{mm})$} & \multicolumn{5}{c}{ Width $(\mathrm{mm})$} \\
Stage & No. & Min. & Max. & Mean $(+\mathrm{SE})$ & Min. & Max. & Mean+SE_ \\
& & & & & & & \\
Egg & 20 & 0.75 & 1.0 & $0.85 \pm 0.02$ & 0.30 & 0.4 & $0.36 \pm 0.01$ \\
1st instar & 20 & 2.1 & 4.0 & $3.26 \pm 0.12$ & 0.45 & 2.1 & $1.28 \pm 0.12$ \\
2nd instar & 20 & 5.6 & 6.5 & $6.09 \pm 0.13$ & 0.75 & 3.0 & $1.84 \pm 0.13$ \\
3rd instar & 20 & 12.0 & 20.0 & $16.34 \pm 0.50$ & 1.6 & 5.2 & $3.21 \pm 0.22$ \\
4th instar & 20 & 20.0 & 27.0 & $23.98 \pm 0.43$ & 2.80 & 7.1 & $5.03 \pm 0.27$ \\
5th instar & 20 & 30.5 & 40.8 & $35.63 \pm 0.50$ & 3.90 & 7.3 & $5.63 \pm 0.25$ \\
6th instar & 20 & 33.5 & 41.1 & $37.30 \pm 0.64$ & 4.20 & 8.2 & $6.19 \pm 0.24$ \\
Pupa 20 & 14.6 & 20.3 & $17.45+0.94$ & 2.5 & 3.9 & $3.70+0.02$
\end{tabular}

TABLE 4

Mean head-capsule width of various instar stages of S. n. botanephaga

$\begin{array}{llll}\begin{array}{l}\text { Instar } \\ \text { stage }\end{array} & \begin{array}{l}\text { Mean head capsule } \\ \text { width }+ \text { SE }(\mathrm{mm})\end{array} & \begin{array}{l}\text { Growth } \\ \text { ratio }\end{array} & \text { Range }(\mathrm{mm}) \\ 1 & 0.35 \pm 0.01 & - & 0.29-0.41 \\ 2 & 0.94 \pm 0.02 & 1.45 & 0.15-1.20 \\ 3 & 1.33 \pm 0.02 & 1.59 & 1.10-1.50\end{array}$




$\begin{array}{llll}4 & 1.55 \pm 0.03 & 1.46 & 1.00-1.80 \\ 5 & 1.85 \pm 0.03 & 1.35 & 1.65-2.20 \\ 6 & 2.06+0.03 & 1.29 & 1.85-2.30\end{array}$

The fourth instar larva is pigmented with well developed heavily scleriotized mandibles. It has mean head capsule width of $1.55 \pm 0.03$ and a mean length and width of $23.98 \pm 0.4 \mathrm{~mm}$ and $5.03 \pm 0.3 \mathrm{~mm}$, respectively, with a mean duration of $5.36 \pm 0.2$ (4-7) days. The fifth instar is longer and larger than the fourth. It has a mean length and width of $35.63 \pm 1.1$ and $5.63 \pm 0.2 \mathrm{~mm}$, respectively. The mean head capsule is $1.85 \pm 0.03 \mathrm{~mm}$ with the mean duration 4.0 \pm 0.3 (2-6 days). The sixth instar larva is the largest with a mean length of $37.3 \pm 0.1 \mathrm{~mm}$ and width of $6.2 \pm 0.02 \mathrm{~mm}$. The bristles are very distinct and visible to the naked eye. The sixth instar larva is very active when disturbed. It has a mean head capsule width of $2.06 \pm 0.03 \mathrm{~mm}$.

\section{Larval behaviour}

The first instar larva of $S$. n. botane-phaga does not feed much and produces very little frass. They spent most of their time moving about and exhibited a high tendency to disperse. Their mandibles are not well developed, so they cannot bore into the stem. The mandibles of the second instar larvae are more developed and the presence of more frass indicates that they feed more than the first instar larvae. The third, fourth, fifth and sixth instar larvae are usually found inside the stem. They are active feeders with well-developed mouthparts for feeding, and produce large quantities of frass.

\section{Larval mortality}

The larval mortality of $S$. $n$. botanephaga varied with larval development up to the last instar. The differences in mortality at different stages of larval development were statistically significant. The highest mortality occurred at the early instars (first and second instars) and the lowest mortality at the fifth and sixth instars (Fig. 4). 


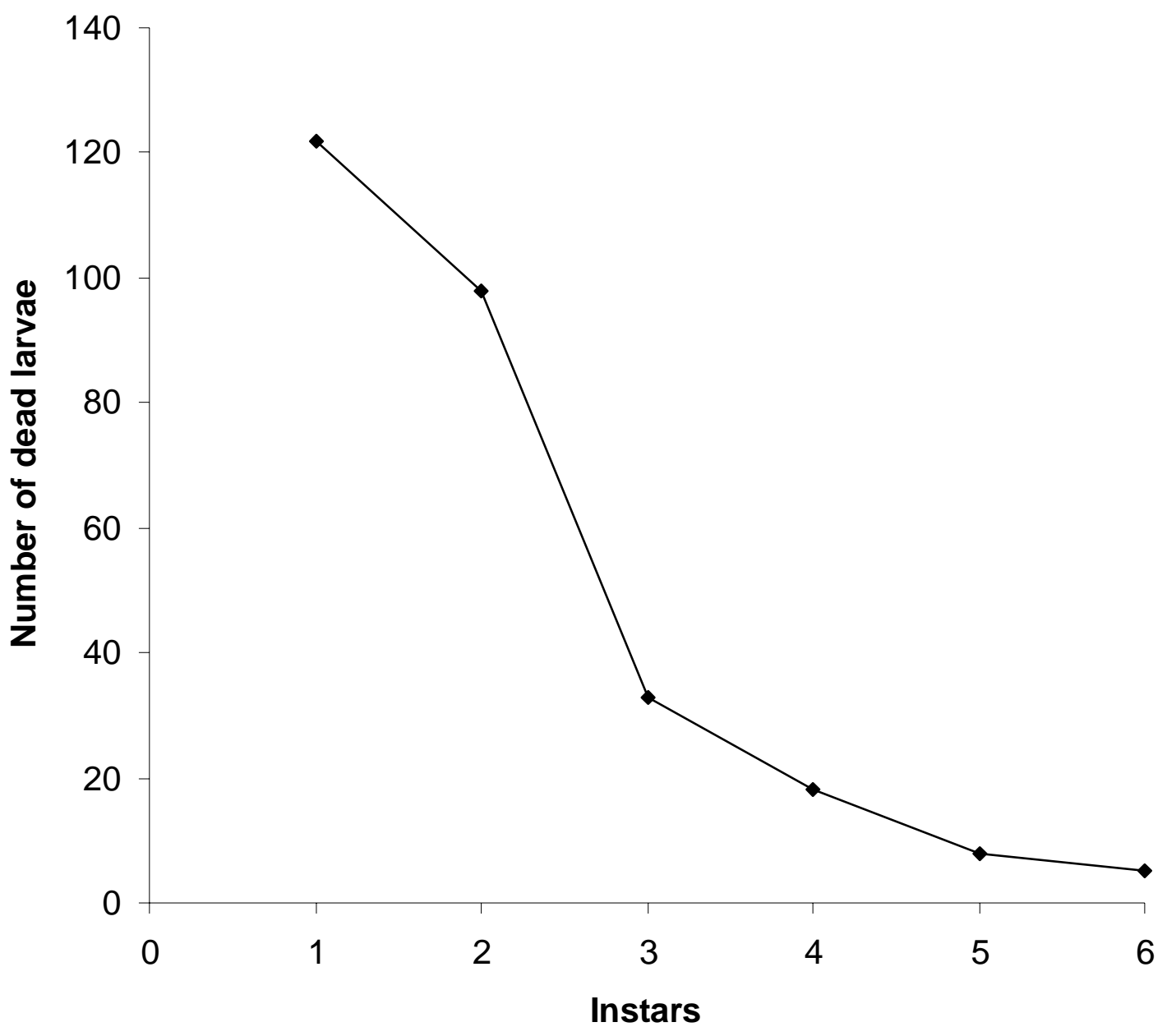

\section{Fig. 4: Larval mortality of S. n. botanephaga in the laboratory}

The pupal stage

The newly formed pupa is pale brown and immobile but shows wiggling movement of the abdomen when touched. It can roll on its sides as well. Usually pupation takes place in the stem. The pupa of $S$.n. botanephaga has a mean weight of $1.98 \pm 1.70 \mathrm{~g}$ with a mean duration of $8.12 \pm 0.08$ (6-9) days. They have mean length and width of $17.45 \pm$ $0.94 \mathrm{~mm}$ and $3.70 \pm 0.02 \mathrm{~mm}$, respectively. Pupal mortality under laboratory conditions is very low (1\%).

\section{Adult stage}

The head of $S$. $n$. botanephaga adult is light to dark brown. The prothoracic shield is also light brown. The dorsal surface of the metathorax, mesothorax and the abdominal segments 1-9 are pinkish. The female and male have a mean length of $16.2 \pm 0.04$ and $15.7 \pm 0.02 \mathrm{~mm}$, respectively. Females have filiform antennae while the males have bipectinate antennae. The females (both mated and unmated) do not lay eggs on the first night after emergence. The mean adult life for the males and females were $8.7 \pm 0.6$ (6-10) days and $9.1 \pm 0.08$ (7-11) days, respectively. The difference between the two was statistically not significant. It was also noted that the unmated females lived longer by 1-2 days than the mated females.

\section{Sex ratio}

S. $n$. botanephaga reared in the laboratory had a sex ratio of approximately 2:3 (176 males: 265 females), and the difference was significant $(P<0.05)$.

\section{Discussion}

Eldana saccharina and Sesamia species are serious pests of maize in Ghana (Aikins, 1957; Scheibelreiter, 1980; Sampson, 1982; Kwapong, 1990). In the present study E. saccharina and Sesamia species were present on maize 
plants in all areas sampled for stem borers. This clearly indicates that the presence of these insects is independent of the location.

The most important species of stem borers found in the Central Region during the minor season were $E$. saccharina, Sesamia species and Chilo aleniellus. Chilo aleniellus was more abundant in the major season. BorketyLa (1995) reported that in the major season, C. aleniellus was the most predominant stem borer species in the coastal savanna of Ghana. Kwapong (1990) made similar observation in his studies on the bionomics of E. saccharina in the Central Region of Ghana.

Sesamia species reported in Ghana include Sesamian. botanephaga (Endrody-Younga, 1968; Leyenear \& Hunter, 1977) and S. calamistis (Sampson, 1982). S. $n$. botanephaga was found to cause $90 \%$ of 'dead heart' in all the areas where stem borers were collected (Ateyim, 1999). Leyenaar \& Hunter (1977) also reported S. botanephaga to cause 63\% loss in the yield of maize in the coastal savanna of Ghana. C. aleniellus discovered on maize in Ghana in 1990 (Gounou et al., 1993) was found to be more predominant in the major season than minor season. Contrary to the observations made by Baidoo (1996) that C. aleniellus was completely absent in the minor season, this work showed that $C$. aleniellus is present on maize in both seasons.

The adult females of $S$. $n$. botanephaga ensure survival of the species by depositing a large number of eggs ( $330 \pm$ 14.7) within a short oviposition period of 5 days. Mating occurs on the first night after emergence and eggs are laid from the second night to the sixth night with the third night being the peak oviposition period. Most of the eggs were deposited on the middle portion of the plants in the inner side of leaf sheath, which fit tightly onto the maize stem close to the edge. The eggs were held together and secured to the substrate by a fluid, which is exuded by the female just before the eggs are deposited. There is the tendency for adult female $S$. $n$. botanephaga to conceal the eggs. This is a highly adaptive phenomenon to ensure the safety and survival of the eggs. This is possible because the females possess telescopic ovipositors. Before the eggs are laid, the female probes the substratum with the ovipositor (Waiyaki, 1971; Girling, 1978). In the field, the tendency to lay eggs on the inner surface of the tight fitting sheath is very important for egg survival.

The important factors influencing the developmental period, egg production and longevity in insects has been reviewed by Johansson (1964) and Engleman (1964). Their findings indicate that mating stimulates oviposition and affects longevity of the females. Virgin females of Sesamia spp. and B. fusca laid fewer eggs and lived longer than mated females (Johansson, 1964; Odhiambo \& Arora, 1973). In the present study the mated females of S. $n$. botanephaga laid more eggs than the virgin females.

The mean incubation period of $S$. $n$. botanephaga observed in this study was $5.23 \pm 0.03$ (5-7 days) in the laboratory with mean maximum and minimum temperature of $32.1 \pm 0.2{ }^{\circ} \mathrm{C}$ and $22.95 \pm 0.6{ }^{\circ} \mathrm{C}$, respectively, at $78.0 \%$ R.H. There are six larval instars, a prepupal and a pupal stage before the adult emerges. Kaufman (1983) observed the same for $S$. calamistis. The larvae migrate to adjacent plants by crawling through overlapping leaves or using the thread, which they have produced. This confirms the findings of Kaufman (1983) who reported that larvae of $B$. fusca migrated to adjacent plants by crawling through overlapping leaves 3-7 days after eclosion.

The pupa is immobile, thus can easily fall prey to natural enemies. This is, however, minimized by the impermeable silken material, which covers the pupa. The newly formed pupa is a pale, cream-colour organism but later darkens to a dark-brown colour before emergence of the adult. It can easily be distinguished from the pupa of $E$. saccharina and $C$. aleniellus by the absence of a dorsal ridge and its uniform pale cream-colour. The adults emerged during the day and at night. According to Girling (1978) the emergence of E. saccharina adults occurred only in the night but occasionally during the day when the pupae are mishandled. Such adults usually have deformed wings.

Infestation by $S$. $n$. botanephaga was high during the minor season especially on the young maize plants causing "dead hearts" when borer population was at its peak due to low rainfall and high tempera-tures. Endrody-Younga (1968) reported that Sesamia infestation in the Ashanti Region of Ghana was negligible in the major season but very high in the minor season causing serious damage to the maize crop. As a result, farmers feel reluctant to plant the minor season maize. Thus, rainfall is an important mortality factor of stem borers in most agro-ecosystems (Sampson \& Kumar, 1983). Kwapong (1990) and Botchey (1984) observed that the population of Sesamia species decreased as the maize became older. This was also confirmed in the present study for $S$. $n$. botanephaga. Heavy rains in the major season could reduce the incidence of stem borers by preventing contact of males and females for mating (Atkinson, 1980), increasing predation and washing off eggs and newly hatched larvae (Harcourt, 1966; Jerath, 1968; Sampson \& Kumar, 1983).

Mating pairs of $S$. $n$. botanephaga re-mained in copula for more than 30 min probably to make sure that the spermato-phore was successfully transferred into the bursa copulatrix of the female. Girling (1978) noted that this process is very important because one mating was sufficient to fertilize the whole egg complements in E. saccharina. On the basis of the total developmental time of $S$. $n$. botanephaga observed during this study, three generations of the pest are possible on a maturing maize plant with average life cycle of 35 days. Sex ratio of both field-collected and laboratory reared $S$. $n$. botanephaga was approxi-mately 2:3. This shows that more females were present in the system than males. This will facilitate the location of mating partners which could lead to rapid pest outbreaks. 


\section{References}

Abu J. F. (1986). A review of stem borers and their control in Ghana. Ghana J. Sci. 14: 107-113.

Adeyemi S. A. O., Donelly J. and Odetoyinbo J. A. (1966). Studies on chemical control of stem borers of maize. Niger agric. J. 3: 61-67.

Aikins J. S. (1957). Dry season investigation of stem borers in the Northern Region. Ghana Fmr 1: 190-191.

Appert J. (1970). Insects harmful to maize in Africa. Madagascar Inst. Agron. Res 5: 210-219.

Ateyim T. S. S. (1999). Some aspects of the biology of Sesamia nonagrioides botanephaga and Chilo aleniellus in southern Ghana. (MPhil. Thesis.) African Regional Postgraduate Programme in Insect Science (ARPPIS), University of Ghana, Legon. 126 pp.

Atkinson P. R. (1980). On the biology, distribution and natural host plants of Eldana saccharina Walker (Lepidoptera: Pyralidae). J. Entomol. Soc. S. Afr. 43 (12): 171-194.

Baidoo P. K. (1996). The susceptibility of five maize varieties to the lepidopterous pest complex and the effect of Baccilus thurigiensis (Berliner) on the stem borer infestation on maize. (MPhil. Thesis.) University of Cape Coast, Cape Coast, Ghana. 112 pp.

Borketey-La E. B. (1995). Earwig Diaperasticus erythrocephalus Oliver (Dermaptera: Forticulidae) as a potential biological control agent of the stem borer complex of maize in Central Region of Ghana. (MPhil. Thesis.) University of Cape Coast, Ghana. 123 pp.

Botchey M. A. (1984). Population pattern of stem borers on maize. ICIPE 12th Annual Report, 1984.

Bowden J. (1956). New species of African stem-boring Agrotidae (Lepidoptera). Bull. Entomol. Res. 47: 415-428.

Bowden J (1976). Stem borer ecology and strategy for control. Ann. appl. Biol. 84: 107-134.

Breniere J. (1971). The problems of lepidopterous stem borers of cereals in West Africa. Ann. zool. Ecol. 3: 287296.

Byerlee D. and Saad, L. (1993). CIMMYT'S Economic environment of 2000 and beyond. A revised forecast Draft paper. Mexico, DF CIMMY

Endrody-Younga, S. (1968). The stem borer, Sesamia botanephaga Tam and Bowden (Lepidoptera: Noctuidae) and the maize crop in Central Ashanti, Ghana.Ghana Jnl agric. Sci. 1: 103-131.

Englemann F. (1964). Inhibition of egg maturation in a pregnant viviparous cockroach. Nature., Lond. 202: 724-725.

FAO (1992). Food and Agricultural Organization statistic series, 104 (45): 265 pp.

Girling D. J. (1978). The distribution and biology of Eldana saccharina Walker (Lepidoptera:) and its relationship to other stem borers in Uganda. Bull. Entomol. Res. 68: 471-488.

Girling D. J (1980). Eldana saccharina as a crop pest in Ghana. Trop. Pest Mgmt 26: 152-156.

Gounou S., Schulthess F., Shanover T., Hammond W. N. O., Braima H., Olaleye I., Cudjoe A. R., Adjakloe R. and Antwi K. K. (1993). Stem and ear borers in Ghana. Ibadan, Nigeria: Plant Health Management Division, Research Monograph, International Institute of Tropical Agriculture.

Harcourt D. G. (1966). Sequential sampling for use in control of the cabbage Looper on Cauliflower. J. Econ. Entomol. 59: 1190-1192.

IITA (1991). Annual Report1990. Nigeria: IITA Ibadan. 64 pp.

Jerath M. L. (1968). Seasonal abundance and distribution of sugarcane stem borers in Nigeria. J. econ. Entomol. 61: 693-696.

Johansson A. S. (1964). Feeding and nutrition in reproduction process in insects. Rev. Entomol. Soc. Am. 2: 43-55.

Kaufmann T. (1983). Observation on the host plant adaptation of Buseola fusca (Lepidoptera: Noctuidae) in Nigeria. Entomol. Soc. Washington.

Kwapong, P. K. (1990). The bionomics of Eldana saccharina and the effects of intercropping and time of planting on stem borer complex on maize in the Central region of Ghana. (MSc. Thesis.) University of Cape Coast. 124 pp.

Leyenaar P. and Hunter R. B. (1977). Effect of stem borer damage on maize yield in the coastal savannah zone of Ghana. Ghana Jnl agric Sci. 10: 67-70.

Lisa C. M., Amani E. E. O. and Jensen H. H. (2000). The geography and causes of food insecurity in developing countries. Agric. Econ. 22: 199-215.

Odhiambo T. R. and Arora G. K. (1973). A comparative study of oocyte development in cotton stainer (Dysdercus spp: Pyrrbocoridae) and the factors that control egg production. Entomologia experimentalis et Applicata 61: 455-470.

Sampson M. A. (1982). The Biology of the Lepidopterous stem borers on sugarcane

(Saccharum officiarum L.) in Ghana. (PhD. Thesis.) Univ. of Ghana, Legon.

Sampson, M. A. and Kumar R. (1983). Population dynamics of stem borer compex on sugar cane in Southern Ghana. Insect Science and Its Applica-tions 4: 25-32.

Sampson, M. A. and Kumar R. (1984). Borer damage and estimation of loss caused by sugarcane stem borers in Southern Ghana. Insect Science and Its Applications 16 (6): 705-710. 
Scheibelreiter Von G. K. (1980). Sugarcane stem borer (Lepidoptera: Noctuidae and Pyralidae) in Ghana. 2 Angew Entomologie 89: 87-99.

Tams, W. H. T. and Bowden, J. (1953). A revision of African species of Sesamia Guenee and related genera (Agrotidae: Lepidoptera). Bulletin of Entomological Research 43: 645-678.

Usua, E. J. (1968). The biology and ecology of Busseola fusca and Sesamia sp. in South Western Nigeria. Distribution and population studies. Journal of Economic Entomology 61: 830-833.

Waiyaki J. W. (1971). The biology and control of the principal Lepidopterous borers associated with sugar cane at Tanganyika Planting Company, Arusha Chini. Miscellaneous Report No. 653 (unpublished). 